\title{
Invenção da América, colonialidade do poder e pós-colonialismo: reflexões acerca do primitivo Novo Mundo ${ }^{1}$
}

\author{
Invención de América, colonialidad del poder y poscolonialismo: \\ reflexiones sobre el primitivo Nuevo Mundo
Invention of America, coloniality of power and post-colonialism: reflections about the primitive New World

\author{
Rodrigo de Morais Guerra²
}

\begin{abstract}
Resumo
O presente trabalho tem como objetivo discutir a noção de invenção do continente americano (América Latina, mais precisamente) a partir de uma perspectiva eurocentrista do conhecimento. Investigamos, pois, como ocorreu o surgimento da América e o que implicou ela ter sido conceituada tal qual como América. Para tanto, dispomos da noção de colonialidade do poder para compreendermos a amplitude do colonialismo que afligiu o continente americano, como tal poder despojou os povos originários de suas respectivas culturas; como se estruturou, a partir da América, uma noção de mundo no qual o europeu passou a ser referência; e como, a partir do advento da colonização, os povos latino-americanos (e demais povos não-europeus, em escala global) passaram a representar o passado, ou seja, o primitivo. Nossos objetivos, desta maneira, consistem em evidenciar como o poder colonial subjugou os povos da América não só nos sentidos mais recorrentemente tratados, como na exploração do trabalho e das riquezas materiais, mas, também, subjugou os povos da América de suas formulações teórico-epistemológicas, culturais e identitárias, apontando, assim, para a construção de uma concepção global de mundo na qual a modernidade é sinônimo de Europa - e, mesmo o que foi colocado como "Novo Mundo", ainda traduz-se como arcaico - e propondo uma mais ampla assimilação das identidades, culturas e epistemologias latino-americanas e das estruturas que compõem o sistema capitalista moderno.
\end{abstract}

Palavras-Chave: Colonialismo; História da América; História do Tempo Presente; Pós-colonialismo.

\section{Resumen}

El presente trabajo tiene como objetivo discutir la noción de invención del continente americano (América Latina, más precisamente) desde una perspectiva eurocéntrica del conocimiento. Por lo tanto, investigamos cómo se produjo la aparición de América y lo que implicaba que se había conceptualizado como América. Para hacerlo, tenemos la noción de colonialidad de poder para comprender el alcance del colonialismo que afligió al continente americano, ya que tal poder despojó a los pueblos originarios de sus respectivas culturas; cómo, desde América, se estructuró una noción de mundo en la que el europeo se convirtió en una referencia; y cómo, desde el advenimiento de la colonización, los pueblos latinoamericanos (y otros pueblos no europeos a escala global) llegaron a representar el pasado, es decir, lo primitivo. Nuestros objetivos de esta manera son mostrar cómo el poder colonial subyugó a los pueblos de América no solo en los sentidos más recurrentemente tratados, sino también en la explotación de la riqueza laboral y material, sino que más bien subyugó a los pueblos de América de su teoría. epistemológicos, culturales e identitarios, señalando así la construcción de una concepción global

\footnotetext{
${ }^{1}$ Artigo apresentado durante o I Congresso Internacional Online de Estudos sobre Culturas - \#Culturas, realizado de forma online, em outubro de 2019.

${ }^{2}$ Mestrando no Programa de Pós-Graduação em História; Universidade Federal do Rio Grande do Norte (UFRN); Natal, Rio Grande do Norte, Brasil; rodrigo.morais.guerra@gmail.com.
} 
del mundo en la que la modernidad es sinónimo de Europa, e incluso lo que se ha llamado "Nuevo Mundo" todavía se traduce como arcaico, y propone una asimilación más amplia de las identidades, culturas y epistemologías latinoamericanas, y de las estructuras que conforman el sistema capitalista moderno.

Palabras claves: Colonialismo; Historia de América; Historia del Tiempo Presente; Poscolonialismo.

\begin{abstract}
This paper aims to discuss the notion of invention of the American continent (Latin America, more precisely) from a Eurocentric perspective of knowledge. Let us therefore investigate how the emergence of America occurred and what it implied to have been conceptualized as America. To this end, we have the notion of coloniality of power to understand the breadth of colonialism that has afflicted the American continent, how such power has stripped the original peoples of their respective cultures; how was a notion of the world structured from America on which the European became a reference; and how, from the advent of colonization, Latin American peoples (and other non-European peoples on a global scale) came to represent the past, that is, the primitive. Our goals, therefore, are to show how colonial power has subjugated the peoples of America not only in the most recurrently treated senses, but also in the exploitation of labor and material wealth, but also subjugated the peoples of America from their theoretical formulations. epistemological, cultural and identity identities, thus pointing to the construction of a global conception of the world in which modernity is synonymous with Europe - and even what has been placed as a "New World" still translates as archaic - and proposing a broader assimilation of Latin American identities, cultures and epistemologies and the structures that make up the modern capitalist system.
\end{abstract}

Keywords: Colonialism; History of America; History of the Present Time; Postcolonialism.

"Estranha modernidade esta que avança para trás. O pôr do Sol do século XX tem mais semelhanças com seus brutais séculos antecessores do que com o futuro plácido e racional de alguns romances de ficção científica." Subcomandante Insurgente Marcos $^{3}$

\title{
1. A Invenção da América e as bases coloniais
}

"Real, verdadeira e literalmente a América, como tal, não existe, apesar da existência da massa de terras não submersas que, no decorrer do tempo, acabará por lhe atribuir esse sentido, esse significado" (O'GORMAN, 1992, p. 99). Ao fazer tal afirmação, Edmundo O’Gorman suscitou um profícuo debate que é tão profundo quanto fascinante: o descobrimento da América... como invenção ${ }^{4}$. A partir da obra de O’Gorman “A Invenção da

3 SUBCOMANDANTE INSURGENTE MARCOS. 7 piezas sueltas del rompecabezas mundial (El neoliberalismo como rompecabezas: la inútil unidad mundial que fragmenta y destruye naciones.), México, 2000. Disponível em: <https://enlacezapatista.ezln.org.mx/1997/06/20/7-piezas-sueltas-del-rompecabezasmundial-el-neoliberalismo-como-rompecabezas-la-inutil-unidad-mundial-que-fragmenta-y-destruye-naciones/> . Acesso em 05 de mar. de 2020. Tradução do autor.

${ }^{4}$ Sobre o termo invenção na História, Durval Muniz mostra que: "No campo da historiografia, este termo [invenção] ganha destaque com o progressivo afastamento dos historiadores em relação às explicações que remetiam para o emprego de categorias trans-históricas, das abordagens metafísicas ou estruturais, que tendiam a enfatizar a permanência, a continuidade e pressupunham a existência de uma essência, de um núcleo significativo da História, de determinadas relações ou processos como sendo determinantes de toda a variedade 
América", podemos, pois, ir além das interpretações históricas cristalizadas que tratam o continente americano como uma descoberta europeia, logo, sujeito a dominação dos espanhóis e portugueses - o que engloba terras, povos, identidades, epistemologias e aspectos outros. Diferentemente do cômodo e simplista prisma da tradicional historiografia positivista, O’Gorman lança luz sobre uma possibilidade, até então, encoberta nos debates da história do continente: a América não poderia ter sido descoberta, pois não existia; a América, isto posto, foi inventada; a América só passa a existir quando conceituada tal qual América; a América, portanto, não à toa, é uma invenção europeia e, sendo assim, é despojada de toda a sua "americanicidade original" aquela porção de terras, aquele novo continente.

Dirimida a pretensa ideia da centralidade do continente europeu no mapa terrestre, a América surge como um novo continente que reclama seu reconhecimento, sua identidade e que é elaborada por meio "de um complexo processo ideológico que acabou, através de uma série de tentativas e hipóteses, por atribuir-lhes um sentido peculiar e próprio: o sentido do ser da 'quarta parte' do mundo" (O'GORMAN, 1992, p. 178). Desta forma, dialogando com Edmundo O'Gorman, no sentido de que a concepção de América foi fruto de uma invenção, de uma conceitualização, a partir de um viés de mundo eurocêntrico, Aníbal Quijano (2005) argumenta que foi a partir de tal conceitualização e, consequentemente, emergência da América, que um novo padrão de poder passou a exercer e balizar as relações sociais mundo afora, o que o mesmo traduz como colonialidade do poder $^{6}$ : a partir da ideia de raça, a qual o autor trata como "uma construção mental que expressa a experiência básica da dominação colonial e que desde então permeia as dimensões mais importantes do poder mundial, incluindo sua racionalidade específica, o eurocentrismo" (QUIJANO, 2005, p. 117) o modelo

do acontecer histórico. [...] o uso do termo invenção remete para uma abordagem do evento histórico que enfatiza a descontinuidade, a ruptura, a diferença, a singularidade, além de que afirma o caráter subjetivo da produção histórica”. ALBUQUER JUNIOR, Durval Muniz de. História: a arte de inventar o passado. Ensaios de teoria da história: Bauru, SP: Edusc, 2007, p. 20.

${ }^{5}$ Ressaltamos as aspas em função de reconhecermos que a própria noção de "americanicidade" parte de uma perspectiva colonial, todavia, utilizamos o termo para destacar o despojo dos povos originários da "América" de todos os aspectos e complexidades de suas culturas e identidades próprias.

${ }^{6}$ Dialogando com Aníbal Quijano, Walter Mignolo aponta a distinção entre o colonialismo e a colonialidade, o primeiro sendo a tomada empírica propriamente dita dos territórios e o segundo a colonização do imaginário e do saber, o que fomentou a colonialismo interno nos países latino-americanos, mesmo pós-independência. MACHADO, João Victor Sanches da Matta. Para (re) pensar a América Latina: a vertente descolonial de Walter D. Mignolo. Espaço e Economia: Revista brasileira de geografia econômica [Online], v. 5, n. 3, 05 dez. 2014. Disponível em: <http://journals.openedition.org/espacoeconomia/899>. Acesso em 28 de nov. 2019. 
de mundo - e de homem - europeu passou a ser a medida da modernidade, implicando, por conseguinte, em um padrão de poder, hoje, hegemônico ${ }^{7}$.

Tal qual Quijano, Achille Mbembe (2014) nos mostra que o conceito de raça foi útil para associar as humanidades não europeias à condição natural de degradação do ser, segundo o autor

\begin{abstract}
A noção de raça permite que se representem as humanidades não europeias como se fossem um ser menor, o reflexo pobre do homem ideal de quem estavam separadas por um intervalo de tempo intransponível, uma diferença praticamente insuperável. Falar delas é, antes de mais nada, assinalar uma ausência - a ausência do mesmo - ou ainda uma presença segunda, a de monstros e de fósseis (MBEMBE, 2014, p. 39).
\end{abstract}

Destarte, a invenção da América constitui um marco paradigmático para o exercício de um novo padrão de poder mundial, incidindo, diretamente, nas mais diversas esferas das relações sociais históricas. A invenção da América determina a conformação de um "Novo Mundo", porém, que já nasce conceitualizado e naturalizado enquanto primitivo.

\title{
2. Compreendendo o Poder Colonial
}

Tomando como fundamento primeiro a ideia de raça, a colonização seguiu um caminho que não apenas distinguiu os sujeitos históricos enquanto colonizados ou colonizadores, mas, de mesmo modo, naturalizou esta distinção numa condição de superiores e inferiores, de modernos e primitivos. Apoiando-se nesta distinção, o capitalismo surgiu como uma nova estrutura de controle do trabalho, de modo que, todas as formas de controle e de exploração do trabalho também estavam associadas à condição naturalizada colonial dos sujeitos envolvidos. Ou seja, as novas identidades históricas produzidas sob a ideia de raça foram associadas à natureza dos papéis e lugares na nova estrutura global de controle do trabalho, fomentando uma relação estruturalmente associada entre raça e divisão do trabalho, culminando com a imposição de uma sistemática divisão racial do trabalho, bem como, das relações sociais no mundo moderno ocidental (QUIJANO, 2005). Isto posto, o dito "Novo Mundo", "descoberto" pelos europeus, já nasce enquanto um mundo primitivo, pois colonizado.

\footnotetext{
7 A partir do século $\mathrm{XX}$, os Estados Unidos também assumem essa imagem atrelada ao desenvolvimento/modernidade, reproduzindo, destarte, os padrões econômicos e ideológicos neoliberais no globo.
} 
A partir da compreensão da América enquanto este "novo mundo" conceituado com base em uma visão hegemônica eurocêntrica, fundamentada na ideia de raça e estruturada nas relações de trabalho capitalista, toda a modernidade dos países de passado colonial passa a ser balizada por esses termos. Com a consolidação da estrutura econômica capitalista, a noção de raça que determinava os povos nativos como povos atrasados, passa a ser aplicada, de mesmo modo, aos países colonizados, estabelecendo uma configuração do sistema mundial capitalista a partir do que Immanuel Wallerstein (1974) trabalhou como o sistema-mundo, ou seja, define-se uma estrutura hierárquica que engloba os estados-nações numa condição de centro, semiperiferia e periferia, de modo que, os países têm seus papéis econômicos diretamente vinculados a essa categorização de suas condições geográficas, atendendo às necessidades e ordenamentos da economia capitalista, construída sobre a divisão mundial do trabalho - que também atendem essa hierarquização dos países dentro do sistema-mundo. Fazendo com que, segundo Aníbal Quijano (2005)

a Europa não somente tinha o controle do mercado mundial, mas pôde impor seu domínio colonial sobre todas as regiões e populações do planeta, incorporando-as ao "sistema-mundo" que assim se constituía, e a seu padrão específico de poder. Para tais regiões e populações, isso implicou um processo de re-identificação histórica, pois da Europa foram-lhes atribuídas novas identidades geoculturais. [...] $\mathrm{Na}$ produção dessas novas identidades, a colonialidade do novo padrão de poder foi, sem dúvida, uma das mais ativas determinações (p. 121).

Por conseguinte, o sistema-mundo capitalista moderno, não pode ser entendido sem a invenção da América, sem a compreensão da relação de reciprocidade entre colonialismo e modernidade, na qual um alavanca o outro.

Para além da dominação e colonização no plano econômico, os efeitos do colonialismo foram muito mais amplos. Ao se estabelecer o europeu como modelo de modernidade, todas as manifestações que remetessem aos povos colonizados estiveram, diretamente, associadas ao passado. Portanto, para que a humanidade ocidental pudesse alcançar a modernidade, a civilização, a iluminação, todos os elementos que remetessem à cultura, à produção científica, às interações entre homem e natureza, às relações de sociabilidades, em suma, às formas de viver o mundo, deveriam estar de acordo com as perspectivas de civilização europeia. Com isso, todas as formas de controle da subjetividade foram submetidas ao poder hegemônico eurocêntrico colonial, corroborando o colonialismo como, também, uma dominação epistemológica, como afirmou Boaventura de Sousa Santos: “o colonialismo, para além de todas as dominações por que é conhecido, foi também uma dominação epistemológica, uma relação extremamente desigual de saber-poder que conduziu 
à supressão de muitas formas de saber próprias dos povos e/ou nações colonizadas" (SANTOS, 2009, p. 13).

Isto posto, com o estabelecimento do domínio nas relações econômicas, bem como na conformação de uma tradição colonial, a partir da qual a medida de desenvolvimento passou a ser a medida europeia, os Estados latino-americanos, ainda que independentes, perpetuaram o colonialismo em seus projetos e práticas políticas, através de um colonialismo interno, ou seja, na medida em que há, em uma mesma nação, uma heterogeneidade étnica, a partir da qual se associam determinadas etnias com os grupos e classes dominantes, e outras com os dominados (GONZÁLEZ CASANOVA, 1969, p. 89 apud FUENTEZ SÁNCHEZ, 2019, p. 27). Sendo assim, por si só, a independência dos países latino-americanos não significou em plena independência do colonialismo imperante em suas relações e projetos de modernidade, de modo que

o processo de independência dos Estados na América Latina sem a descolonização da sociedade não pôde ser, não foi, um processo em direção ao desenvolvimento dos Estados-nação modernos, mas uma rearticulação da colonialidade do poder sobre novas bases institucionais (QUIJANO, 2005, p. 135).

Acarretando, desta forma, em demandas e embates históricos, que permanecem como uma continuidade do colonialismo, até o tempo presente, tais como a luta camponesa pelo acesso à terra; a luta indígena pela autonomia e autodeterminação; a luta dos negros que carregam uma pesada bagagem histórica dos seus povos escravizados; a luta das mulheres; a luta, em suma, das minorias que levantam distintas bandeiras, mas que, em suas raízes, traduzem suas lutas no combate às formas coloniais de dominação.

\section{Para seguirmos pensando: o Despertar Pós-Colonial}

Fundada sobre o eixo principal da categoria de raça, a compreensão e retomada do processo histórico que surge com a América e se estabelece como um novo padrão de poder hegemônico se faz mister para assimilarmos as identidades, culturas e resistências latinoamericanas, bem como as estruturas que compõem o sistema capitalista moderno. Em suma, investigar tais facetas do processo histórico, compreendendo a América enquanto invenção eurocêntrica e, logo, dotada de um sentido que satisfizesse seus interesses, bem como da nova ordem de poder estabelecida, promovendo uma continuidade de longa duração histórica (BRAUDEL, 1992) de um poder colonial, é indispensável para novas abordagens e interpretações históricas acerca desse passado que configurou o "Novo Mundo", já em sua 
gênese, como algo primitivo, ultrapassado, desprovido de valores que caminhassem em direção à modernidade.

Em resposta aos mais distintos despojos efetuados pela colonização, percebemos, hoje, a insurgência de novas práticas e discursos que buscam superar a imposição colonial incrustrada nas estruturas e mentalidades do mundo ocidental moderno. Como exemplo deste movimento, o sociólogo português Boaventura de Sousa Santos aponta para as Epistemologias do Sul como "um convite a um amplo reconhecimento das experiências de conhecimentos do mundo" (2009, p. 18), de modo que as Epistemologias do Sul consistem em:

novos processos e novas relações que se organizam a partir das práticas das classes e dos grupos sociais que sofreram de maneira sistemática a destruição, a opressão e a discriminação causadas pelo capitalismo, pelo colonialismo e por todas as naturalizações da desigualdade em que se tenha desdobrado, sejam elas o valor de troca, a propriedade individual da terra, o sacrifício da Mãe Terra reduzida à natureza inerte, o racismo, o sexismo, o individualismo, o material como superior ao espiritual e todos os demais fundamentalismos econômicos, políticos e culturais que tentam bloquear a imaginação emancipatória e desacreditar a luta pelas alternativas (SANTOS, Boaventura de Sousa. Prólogo. In: LEYVA, 2015, p. 12-13. Tradução do Autor)

As Epistemologias do Sul, portanto, surgem no horizonte do mundo moderno ocidental como um verdadeiro "já basta!"” ao colonialismo que perpassou as épocas históricas e permanece regendo as relações de poder não apenas no seio dos países colonizados, mas na organização mundial do mercado capitalista e na manutenção dos países de passado colonial na condição de países "subdesenvolvidos" - numa relação que não seria demasiado absurdo recordar as relações metrópole-colônia.

No plano teórico, de mesmo modo, percebemos uma resposta ao colonialismo a partir das perspectivas pós-coloniais como uma opção frente à monocultura imposta das práticas e do saber. Ainda mais profundos, do ponto de vista epistemológico, a vertente pós-colonial busca descolonizar a ciência e o pensamento, ao passo que, tanto o vocábulo "América" quanto o vocábulo "Latina" sequer deveriam ser admitidos, pois consistem em vocábulos, fundamentalmente, coloniais, trazendo consigo as marcas da Europa, às quais os povos

\footnotetext{
${ }^{8}$ Referência ao levante zapatista quando, no dia 1 de janeiro de 1994 - data que marcava a adesão oficial do México ao NAFTA (North American Free Trade Agreement), bloco econômico dos países do Norte, formado por México, Estados Unidos e Canadá -, guerrilheiros indígenas surgiram das montanhas da Selva Lacandona e tomaram em armas alguns municípios do estado mexicano de Chiapas. Em sua declaração de guerra ao Estado, anunciaram serem produto de mais de 500 anos de lutas, aludindo à estrutura colonial de longa duração histórica, e que "já basta!".
} 
originários jamais se reconheceram. Sendo assim, Mignolo enfatiza que deverá existir num horizonte pós-colonial um "após-América" e um "após-América Latina” (MIGNOLO, 2007 apud MACHADO, 2014, p. 2). Portanto, a ascensão das manifestações pós-coloniais - ou decoloniais - suscitam uma revolução das mais radicais e, porquê não, das mais prementes, para o combate aos colonialismos históricos: a revolução epistemológica. Repensar não apenas as estruturas de poder dominantes, mas, de mesmo modo, repensar a linguagem e todo o campo simbólico de disputas de poder (BOURDIEU, 1989) que foi tomado pelos colonizadores.

Em suma, através da relação recíproca entre o etnocentrismo colonial e a classificação racial, os europeus impregnaram de sentido e valores uma lógica modernista na qual passaram a ser vistos (e a se sentirem) naturalmente enquanto superiores. Com isso, a América não apenas já nasceu sob uma condição de primitiva, como toda a "americanicidade" pertinente a este continente, permaneceu associada à condição de atraso, de passado, de barbárie. Como Quijano (2005) nos mostra, “os europeus geraram uma nova perspectiva temporal da história e re-situaram os povos colonizados, bem como a suas respectivas histórias e culturas, no passado de uma trajetória histórica cuja culminação era a Europa" (p. 121), fazendo com que as raízes culturais e identitárias da América fosse negada e renegada não apenas pelos colonizadores, mas, de mesmo modo, pelos povos dominados por esta monocultura da mente (ALMEIDA, 2010).

Finalmente, assumindo este complexo de vira-latas, o qual concede ao sul ${ }^{9}$ a desejada imagem caricatural do europeu, como acusou Eduardo Galeano ${ }^{10}$, devemos resgatar as raízes mais profundas que foram destituídas de valor pelo projeto colonial e "nos libertarmos do espelho eurocêntrico onde nossa imagem é sempre, necessariamente, distorcida. É tempo, enfim, de deixar de ser o que não somos" (QUIJANO, 2005, p. 139). É tempo, em suma, do despertar pós-colonial.

\footnotetext{
${ }^{9}$ Seguindo as linhas de Boaventura de Sousa Santos, interpretamos o "sul" não como, necessariamente, uma determinação geográfica, mas, sim, enquanto uma representação do mundo colonizado e, de mesmo modo, das resistências. Sendo assim, para além de uma condição estritamente geográfica, o "sul" pode se encontrar no Norte Global, nas manifestações de populações excluídas, silenciadas, marginalizadas, contrárias ao colonialismo. O "sul", portanto, assume aqui a forma de uma expressão anticolonial. SANTOS, Boaventura de Soua. Prólogo. In: LEYVA, Xochitl et al. Prácticas otras de conocimiento(s): Entre crisis, entre guerras (Tomo I). San Cristóbal de Las Casas: Cooperaiva Editorial Retos, 2015.
}

${ }^{10}$ NOSSA AMÉRICA. São Paulo: Revista do Memorial da América Latina, v. 52, 2015. 


\section{Referências}

ALMEIDA, Maria da Conceição de. Complexidade, saberes científicos, saberes da tradição. São Paulo: Livraria da Física, 2010.

BOURDIEU, Pierre. O poder simbólico. Tradução Fernando Tomaz. Lisboa: Difel, 1989.

BRAUDEL, Fernand. A longa duração. In: Escritos sobre a História. Lisboa: Perspectiva, 1992.

FUENTES SÁNCHEZ, Waldo Lao. Autonomías indígenas: resistencias y luchas por el reconocimiento en Nicaragua y México. Buenos Aires: El Colectivo, 2019. 204 p.

LEYVA, Xochitl et al. Prácticas otras de conocimiento(s): Entre crisis, entre guerras (Tomo I). San Cristóbal de Las Casas: Cooperaiva Editorial Retos, 2015. 487 p.

MACHADO, João Victor Sanches da Matta. Para (re) pensar a América Latina: a vertente descolonial de Walter D. Mignolo. Espaço e Economia: Revista brasileira de geografia econômica [Online], v. 5, n. 3, 05 dez. 2014. Disponível em: <http://journals.openedition.org/espacoeconomia/899>. Acesso em 28 de nov. 2019.

MBEMBE, Achille. Crítica da Razão Negra. Lisboa: Antígona, 2014.

NOSSA AMÉRICA. São Paulo: Revista do Memorial da América Latina, v. 52, 2015.

O’GORMAN, Edmundo. A invenção da América. São Paulo: Unesp, 1992

QUIJANO, Aníbal. Colonialidade do poder, eurocentrismo e América Latina. In.: LANDER, Edgardo (org.). A Colonialidade do Saber - Eurocentrismo e Ciências Sociais - Perspectivas Latino-americanas. Buenos Aires: Clacso, 2005.

SANTOS, Boaventura de Sousa; MENESES, Maria Paula (orgs.). Epistemologias do sul. Coimbra: Almedina, 2009.

SUBCOMANDANTE INSURGENTE MARCOS. 7 piezas sueltas del rompecabezas mundial (El neoliberalismo como rompecabezas: la inútil unidad mundial que fragmenta y destruye naciones.), México, 2000.2 Disponível em: <https://enlacezapatista.ezln.org.mx/1997/06/20/7-piezas-sueltas-del-rompecabezas-mundialel-neoliberalismo-como-rompecabezas-la-inutil-unidad-mundial-que-fragmenta-y-destruyenaciones/>. Acesso em 05 de mar. de 2020.

WALLERSTEIN, Immanuel. The Modern World System. New York: Academic Press, 1974. 